r ScIDioc

\section{Assessment of Interleukin-33 Gene Variants and Protein Level in Periodontal Disease among Saudi Population}

Research Article

Fathy M. Elfasakhany ${ }^{1,2, *}$, Zahra Alashur ${ }^{3}$, Ebtehal H. Ali ${ }^{1}$

${ }^{1}$ Department of Basic and Clinical Oral Sciences, Faculty of Dentistry, Umm Al Qura University, Makkah, Saudi Arabia.

${ }^{2}$ Department of Medical Biochemistry, Faculty of Medicine, Tanta University, Tanta, Egypt.

${ }^{3}$ Dental intern program, Faculty of Dentistry, Umm Al Qura University, Makkah, Saudi Arabia.

\title{
Abstract
}

Background: Periodontal disease is an infectious disease that affects the teeth supporting structures and finally may lead to tooth loss. Interleukin-33 (IL-33) is a recently identified member of the IL-1 family and it was reported to have a role in immune response, bone homeostasis and osteoclastogenesis.

Objectives: To analyze and correlate the levels of IL-33 in the plasma and the gingival crevicular fluid(GCF) and the intronic single nucleotide polymorphism (rs1929992) in the IL-33 genein a group of Saudi individuals with moderate to severe periodontitis and a healthy control group.

Materials and methods: Seventy unrelated individuals with moderate to severe periodontitis and seventy healthy subjects were included in this study. The periodontal status was assessed based on plaque index, probing depth, bleeding on probing and clinical attachment loss. IL-33 levels were estimated in the GCF and plasma in both groups by ELISA. Peripheral blood was utilized for preparation of genomic DNA that was used for genotyping of IL-33 A/G (rs1929992) using polymerase chain reaction followed by restriction endonuclease digestion.

Results: IL-33 concentration was higher- but not statistically significant- in the GCF of the periodontitis subjects in comparison with the controls $(\mathrm{P}>0.05)$ while the plasma level was the same in both groups $(\mathrm{P}>0.05)$. For the IL-33 rs1929992 polymorphism, the frequencies of the IL-33 genotypes and alleles were indifferent between the control group and the periodontitis group (P > 0.05).

Conclusion: The levels of plasma and GCF of IL-33 could not differentiate between subjects with periodontitis and healthy controls. In addition, the results suggested that IL-33 rs1929992 polymorphism may not have a risk of periodontitis among the Saudis in Makkah environ.

Keywords: Gene Polymorphism; Periodontitis; Interleukin-33; Polymerase Chain Reaction; Restriction Enzyme; ELISA.

\section{Introduction}

Periodontitis is an infectious inflammatory state of the tissues surrounding the teeth [1]. The aetiology of this complex disease is determined by both genetic and the environmental factors (e.g., smoking and stress) $[2,3]$. The most prominent clinical features of the condition are development of microbial plaque, periodontal inflammation and destruction of periodontal tissue and alveolar bone [4]. The incidence and the severity of the disease rise with the age and usually influences every gender evenly. Meanwhile, the periodontal disease is noticeably detected between family members and across different generations within the same family, suggesting that there is a genetic susceptibility to the periodontal disease $[5,6]$. Besides, numerous studies reported the role of gene polymorphisms of several biomolecules especially cytokines in the host response in periodontitis, and in the progress of the disease. Such gene polymorphisms may result in a change in the protein structure or its expression and probably lead to alteration in the innate and adaptive immunity and may thus be deterministic in the outcome of the disease [7]. Cytokines are small polypeptides that have wide range of inflammatory, hematopoetic and immunomodulatory effects. They are produced by several types of cells including lymphocytes, dendritic cells, monocytes, neutrophils, fibroblasts and endothelial cells [8]. Cytokines play

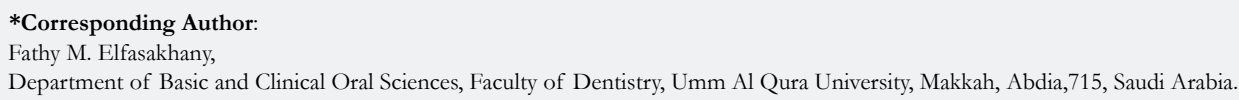

Citation: Fathy M. Elfasakhany, Zahra Alashur, Ebtehal H. Ali. Assessment of Interleukin-33 Gene Variants and Protein Level in Periodontal Disease among Saudi Population. Int J Dentistry Oral Sci. 2020;7(11):997-1002. doi: http://dx.doi.org/10.19070/2377-8075-20000198

Copyright: Fathy M. Elfasakhany ${ }^{\circ} 2020$. This is an open-access article distributed under the terms of the Creative Commons Attribution License, which permits unrestricted use, distribution and reproduction in any medium, provided the original author and source are credited. 
a valuable role in inflammatory conditions like periodontitis and rheumatoid arthritis. Furthermore, it has been reported that IL-1 family cytokines play key roles in inflammation. Recently, it has been suggested that IL-33, an IL-1 family member, could share in the development and sequence of chronic periodontitis [9]. It acts as an alarmin, chemoattractant, and nuclear factor and has been defined to control both innate and adaptive types of immunity [10]. It is constitutively expressed as a nuclear factor in different cells such as fibroblasts, endothelial cells and epithelial cells. Within the nucleus, IL-33 behaves as an endogenous molecule that help to maintain the transcription factor $\mathrm{NFKB}_{\mathrm{K}}$ and thus lowers the expression of genes that encode the inflammatory cytokines thereby guaranteeing tissue homeostasis. Once became extra cellularly upon cell damage, IL-33 works as an alarmin exhibiting proinflammatory properties $[11,12]$. IL-33 performs its action through its ST2 receptors that are expressed in several cells like Th2 lymphocytes, B cells and mast cells resulting in production of pro-inflammatory cytokines $[10,13,14]$. In human, excess IL33 expression was detected in the gingival tissue of subjects with chronic periodontitis and may work as a driving factor to recruit of $\mathrm{B}$ and $\mathrm{T}$ lymphocytes that express RANK-L [15]. However, measuring the IL-33 in the GCF showed conflicting results in subjects affected by chronic periodontitis [16-18]. Furthermore, the study of IL-33 polymorphisms and their association with periodontitis were poorly studied in different ethnic populations and to the best of our knowledge, it is not examined before in Saudi Arabia population. Therefore, we aimed in this study to estimate IL-33 concentrations in the GCF and plasma of the study group and to analyze the relationship between the IL-33 A/G (rs 1929992) single-nucleotide polymorphism (SNP) and the susceptibility to periodontitis among Saudis in Makkah environ.

\section{Materials and Methods}

\section{Study population}

This study included 140 subjects (70 unrelated subjects affected with moderate to severe periodontitis and 70 healthy controls) were recruited from the dental clinic, school of dentistry, Umm AL Qura University, Saudi Arabia. All participants were Saudis. Both groups were matched regarding the age and gender and had at least 20 teeth. The inclusion criteria for selection of the control group were the absence of both periodontal and systemic diseases. The exclusion criteria include systemic diseases, immunodeficiency diseases, previous orthodontic therapy, pregnancy, lactation and smoking. The sample size was determined based on a previous report with respect to the relationship of the IL-33 polymorphism with periodontal disease [19]. The sample size was expanded by approximately $40 \%$ to keep up the estimates at an optimal degree of precision (5\%) against the expected impact of reduction of sample size because of rejections and dropouts.

\section{Periodontal examination}

The periodontal condition of all individuals was assessed based on bleeding on probing depth (PD), probing (BOP), plaque index (PI), and clinical attachment loss (CAL) by two well trained assessors. Individuals with BOP, PD $\geq 5 \mathrm{~mm}, \mathrm{CAL} \geq 3 \mathrm{~mm}$ and radiographic proof of bone damage $\geq 20 \%$ were involved in the patient group. The updated report of the American Academy of periodontology was used to characterize the periodontitis [20].

\section{GCF samples collection}

Two to four sites/individual were sampled to obtain a suitable volume of GCF in healthy subjects. For subjects affected with moderate to severe periodontitis, GCF was collected from two sites with the highest CAL and maximum bleeding score along with radiographic evidence of alveolar bone resorption. GCF samples were collected using microcapillary pipettes as described before [21]. The sample collection area was air dried and protected from saliva contamination by isolating it with sterile cotton rolls. A universal curette was used to remove the supragingival plaque to avoid contamination and obstruction of the microcapillary pipette by plaque. $10 \mu \mathrm{l}$ volumetric microcapillary pipette (Microcapillary pipettes, Drummond Scientific Company, Broomall, USA) was inserted into the gingival sulcus for GCF collection. The collected GCF was mixed with a suitable volume of phosphate buffered saline in a new plastic tube and the dilution range was recorded to be considered during measurement. The GCF samples contaminated with saliva or blood were excluded and discarded. The GCF specimens were kept at $-20^{\circ} \mathrm{C}$ untill the assay time.

\section{Blood sample collection}

Blood specimens were obtained from all participants in K3EDTA (tri-potassium ethylene diamine tetraacetic acid) tubes. The tubes were centrifuged at $1200 \mathrm{~g}$ for $5 \mathrm{~min}$ and the plasma was transferred to a new plastic tube. The white cells buffy coat was used for extraction of DNA. All samples were kept at $-20^{\circ} \mathrm{C}$ until the assay time.

\section{IL-33 assay}

IL-33 levels were measured in the GCF and plasma samples using commercially available human IL-33 enzyme-linked immunosorbent assay (ELISA) kit (ABCAM, Cambridge, USA). Analysis was performed following the manufacturer's protocol.

\section{Genomic DNA extraction}

Peripheral blood leukocytes in the white coat of collected blood samples were used for preparation of DNA using DNA extraction kit (QIAamp, Qiagen, Hilden, Germany) consistent with the instructions of the manufacturer. Extracted DNA was utilized for PCR experiment.

\section{IL-33A/G(rs1929992) genotype frequencies}

IL-33 polymorphism was analyzed using the PCR-restriction fragment length polymorphism as described before [22]. The primers were forward 5'- GAAGTCATCATCAACT'TGGAACC-3' and reverse 5'- GGATTGGAATCCCATGGTC-3'. The PCR program consisted of a denaturation step at $94^{\circ} \mathrm{C}$ for $5 \mathrm{~min}, 35$ cycles: $94^{\circ} \mathrm{C} 30 \mathrm{sec}, 61^{\circ} \mathrm{C} 30 \mathrm{sec}, 72^{\circ} \mathrm{C} 30 \mathrm{sec}$ and an extensionstep at $72^{\circ} \mathrm{C}$ for $5 \mathrm{~min}$. The PCR fragment (217 bp) was digested with SspI restriction enzyme and then visualized under ultraviolet light. Genotypes pattern were: G/G gave a single band of 217 bp; A/A gave 2 bands of $134 \mathrm{bp}$ and $83 \mathrm{bp}$ and AG gave 3 bands of 217 bp, $134 \mathrm{bp}$ and $83 \mathrm{bp}$.

\section{Statistical analysis}


Data were assessed using SPSS version 21 (SPSS Inc., IL, USA). Continuous variables were assessed using Student's t-test, whereas the categorical data were assessed using Chi-squared test. Odds ratio (OR) was calculated with 95\% confidence interval (CI) and $\mathrm{P}$ value $<0.05$ was considered statistically significant for all analyzes.

\section{Results}

\section{Clinical assessment}

Table 1 shows that the control subjects and patients with periodontitis were matched regarding the age and gender. The mean age was $40.27 \pm 4.75$ and $41.35 \pm 3.76$ in controls and periodontitis respectively $(P=0.136)$. The gender $(M / F)$ was $40 / 30$ and $39 / 31$ in controls and periodontitis respectively $(P=0.865)$. The clinical data showed that the mean values of BOP, CAL, PI and PD were significantly higher in subjects with periodontitis in comparison with the controls $(P<0.001)$. This confirmed that the matching between both groups was appropriate (Table 1).

\section{GCF and plasma IL-33 levels}

The results of interleukin 33 level in GCF and plasma are shown in table 1. IL-33 was detected in all GCF and plasma samples. The mean concentration of IL-33 in GCF was19.4 $\pm 3.55 \mathrm{pg} / \mathrm{ml}$ and $20.82 \pm 3.29 \mathrm{pg} / \mathrm{ml}$ in controls and periodontitis subjects respectively $(P=0.169)$. The mean concentration of IL-33 in plasma was $15.87 \pm 3.64 \mathrm{pg} / \mathrm{ml}$ and $16.28 \pm 3.79 \mathrm{pg} / \mathrm{ml}$ in the controls and periodontitis subjects respectively $(P=0.331)$.

\section{IL-33A/G (rs1929992) polymorphism}

The genotypes and alleles frequencies of IL-33A/G polymorphism in both control and periodontitis groups are shown in $\mathrm{Ta}-$ ble 2. The distribution of IL-33 genotypes was in Hardy-Weinberg equilibrium in both groups. For the control subjects, the genotypes GG, AG and AA were $17.14 \%, 32.86 \%$ and $50 \%$ respectively and were $12.86 \%, 38.57 \%$ and $48.57 \%$ respectively in the periodontitis group. The percentages of $\mathrm{G}$ allele were $33.57 \%$ and $32.14 \%$ while $A$ allele was $66.43 \%$ and $67.86 \%$ in the control group and patients with periodontitis respectively. The genotype and allele frequencies of the IL-33 showed no significant differences between the controls and subjects with periodontitis $(P>$ $0.05)$.

\section{GCF and plasma IL-33 levels in different genotypes}

The level of the GCF IL-33 in the GG, AG, AA genotypes of the controls were $19.42 \pm 3.87,19.39 \pm 3.97$ and $19.4 \pm 3.25$ while

Table 1. Demographic, clinical date and IL-33 level in the study population.

\begin{tabular}{|c|c|c|c|}
\hline Characteristics & Control group (70) & Periodontitis group (70) & Pvalue \\
\hline Age (years) & $40.27 \pm 4.75$ & $41.35 \pm 3.76$ & 0.136 \\
\hline Gender $(\mathrm{M} / \mathrm{F})$ & $40 / 30$ & $39 / 31$ & 0.865 \\
\hline BOP $(\%)$ & $8.71 \pm 1.12$ & $46.04 \pm 9.41$ & $<0.001$ \\
\hline PD $(\mathrm{mm})$ & $1.22 \pm 0.51$ & $5.25 \pm 0.71$ & $<0.001$ \\
\hline CAL $(\mathrm{mm})$ & $0.72 \pm 0.21$ & $4.49 \pm 0.59$ & $<0.001$ \\
\hline PI $(\%)$ & $4.76 \pm 0.45$ & $47.94 \pm 3.3$ & $<0.001$ \\
\hline GCF IL-33 $(\mathrm{pg} / \mathrm{ml})$ & $19.40 \pm 3.55$ & $20.82 \pm 3.29$ & 0.169 \\
\hline Plasma IL-33 $(\mathrm{pg} / \mathrm{ml})$ & $15.87 \pm 3.64$ & $16.28 \pm 3.79$ & 0.331 \\
\hline
\end{tabular}

Data are shown as mean \pm SD. $P$-value $<0.05$ was considered as significant.

Table 2. Genotype and allele frequencies of IL-33 A/G Single Nucleotide Polymorphism in the study group.

\begin{tabular}{|c|c|c|c|c|c|c|c|}
\hline & \multicolumn{2}{|c|}{$\begin{array}{l}\text { Control } \\
(n=70)\end{array}$} & \multicolumn{2}{|c|}{$\begin{array}{l}\text { Periodonti- } \\
\text { tis }(n=70)\end{array}$} & \multirow[t]{2}{*}{$P_{\text {value }}$} & \multirow[t]{2}{*}{ Odds ratio } & \multirow[t]{2}{*}{$95 \% \mathrm{CI}$} \\
\hline & No & $\%$ & No & $\%$ & & & \\
\hline \multicolumn{8}{|c|}{$I L-33$ polymorphism } \\
\hline \multicolumn{8}{|c|}{ Genotypes: } \\
\hline GG & 12 & 17.14 & 9 & 12.86 & & 1 & \\
\hline GA & 23 & 32.86 & 27 & 38.57 & 0.391 & 1.565 & $0.56-4.374$ \\
\hline AA & 35 & 50 & 34 & 48.57 & 0.866 & 0.944 & $0.487-1.832$ \\
\hline \multicolumn{8}{|c|}{ Alleles: } \\
\hline G & 47 & 33.57 & 45 & 32.14 & & 1 & \\
\hline A & 93 & 66.43 & 95 & 67.86 & 0.606 & 1.295 & $0.484-3.467$ \\
\hline
\end{tabular}

Chi-square analysis of genotypes between patients with periodontitis and healthy controls. $* P$-value $<0.05$ was considered as significant. 
Table 3. Comparison between IL-33 (rs1929992) geno types with respect to GCF and plasma IL-33 concentrations in the study group.

\begin{tabular}{|c|c|c|c|c|c|c|c|c|}
\hline Study group & $\begin{array}{c}\text { IL-33 polymor- } \\
\text { phism } \\
\text { (rs1929992) }\end{array}$ & Number & $\begin{array}{l}\text { GCF con- } \\
\text { centration }\end{array}$ & $\chi^{2}$ & $P$ & $\begin{array}{l}\text { Plasma IL-33 } \\
\text { concentration }\end{array}$ & $\chi^{2}$ & $P$ \\
\hline \multirow{3}{*}{$\begin{array}{l}\text { Control } \\
\text { group }\end{array}$} & GG & 12 & $19.42 \pm 3.87$ & \multirow{3}{*}{0.157} & \multirow{3}{*}{0.929} & $16.5 \pm 3.09$ & \multirow{3}{*}{1.127} & \multirow{3}{*}{0.569} \\
\hline & $A G$ & 23 & $19.39 \pm 3.97$ & & & $16.22 \pm 3.25$ & & \\
\hline & AA & 35 & $19.4 \pm 3.25$ & & & $15.43 \pm 4.08$ & & \\
\hline \multirow{3}{*}{$\begin{array}{l}\text { Periodontitis } \\
\text { group }\end{array}$} & GG & 9 & $20.78 \pm 4.44$ & \multirow{3}{*}{1.094} & \multirow{3}{*}{0.579} & $16.56 \pm 4.69$ & \multirow{3}{*}{0.323} & \multirow{3}{*}{0.851} \\
\hline & AG & 27 & $20.92 \pm 2.85$ & & & $16.93 \pm 4.12$ & & \\
\hline & AA & 34 & $20.32 \pm 3.36$ & & & $16.12 \pm 3.33$ & & \\
\hline
\end{tabular}

*Kruskal-Wallis test, $\mathrm{P}<0.05$ considered as statistically significant. Data are shown as mean $\pm \mathrm{SD}$.

they were $20.78 \pm 4.44,20.92 \pm 2.85$ and $20.32 \pm 3.36$ in the periodontitis group respectively. The plasma level of IL-33 in the GG, AG, AA genotypes were $16.50 \pm 3.09,16.22 \pm 3.25$ and $15.43 \pm$ 4.08 in the control group while they were $16.56 \pm 4.69,16.93 \pm$ 4.12 and $16.12 \pm 3.33$ in the periodontitis group respectively. The GCF IL-33 level was indifferent between different genotypes in the controls $(P=0.929)$ and the periodontitis group $(P=0.579)$. In addition, the plasma IL-33 level was indifferent between different genotypes in the controls $(P=0.569)$ and the periodontitis group $(P=0.851)$.

\section{Discussion}

Periodontitis is a chronic inflammation of the tooth surrounding tissues that results in damage of the tooth surrounding tissue and alveolar bone due to the interaction of the host immune response to the pathogenic bacteria [1]. The existence of periodontopathic bacteria in combination with elevated levels of the proinflammatory cytokines and low levels of the inflammation inhibitory cytokines and other factors cause the progression of periodontal disease [23]. It is obvious that the cytokines do not work separately but rather as a part of complex networks with diverse activities [24]. Cytokines are released during periodontitis as a result of the immune cells infiltrating the periodontal tissue, which eventually causes periodontal tissue damage [25]. IL-33 is a newly identified member of IL-1 cytokine family. It can work both as a soluble mediator and a nuclear factor. IL-33, as a cytokine, functions as an alarmin which is released upon damage of epithelial or endothelial cells and it can target multiple types of cells thus making the immune system alert to endogenous trauma like infection [26]. On the other hand, it has been shown that there was a relationship between cytokines single nucleotide polymorphisms (SNPs) and the periodontal disease. Such Polymorphisms can alter cytokines production, which in turn may lead to changes in the immune responses and can lead to chronic inflammations [27]. As the IL-1 cytokine family is associated with chronic inflammatory and autoimmune disorders such as rheumatoid arthritis and periodontitis $[28,29]$, we aimed to estimate the IL-33 levels in the GCF and plasma of a group of Saudi individuals with moderate to severe periodontitis and a control group. Furthermore, since IL-33 is a novel cytokine and its gene polymorphisms were poorly studied in the periodontal disease, we investigated the association of the IL-33 A/G rs1929992 SNP and the periodontitis in the study group. The GCF IL-33 level was higher-but not statistically significant-in the periodontitis subjects than the controls while the plasma level of IL-33 was similar in both groups. For the IL-33 A/G rs 1929992 polymorphism, we found no association between IL-33 polymorphism and the risk of periodontitis in the studied Saudi subjects. The GCF and the plasma concentrations of IL-33 were measured in the periodontal disease by several investigators but the results showed remarkable inconsistency. Ballambettu et al (2019) could detect IL-33 in all examined samples and they found that both GCF and plasma concentrations of IL-33 were significantly higher in the aggressive periodontitis than chronic periodontitis or the controls but were indifferent between chronic periodontitis and the controls [19]. This result was consistent with our results regarding chronic periodontitis. Buduneli et al, (2012) found a significant lower level of the IL-33 in the GCF in chronic periodontitis than subjects with healthy periodontium, whereas the total amounts were similar in both groups but the plasma and salivary concentrations of IL-33 showed no difference between the studied groups. They concluded that the IL-33 concentrations in the GCF, saliva or plasma cannot differentiate between chronic periodontitis and healthy individuals [30]. Their results were consistent with our results regarding the plasma IL-33 level. They stated that the episodic nature of the periodontal disease may be a factor and indicated that it could be considered that the quiescent form of periodontal tissue damage in chronic periodontitis subjects lead to absence of significant difference between chronic periodontitis subjects and periodontally healthy subjects in terms of IL-33 concentrations in the biologic fluids. Furthermore, they found that the IL-33 concentration in the GCF was significantly lower in chronic periodontitis subjects than in control subjects. They pointed out that the lower volume of the GCF specimens in the periodontally healthy subjects may explain the significantly higher IL-33 level in the GCF in the healthy subjects than in the chronic periodontitis. Sağlam et al, (2017) found that the total amount of the IL-33 in the GCF was higher in chronic periodontitis compared to the controls while the GCF IL-33 level was lower in chronic periodontitis subjects compared to the controls. They also found that the plasma and salivary IL-33 levels were indifferent between chronic periodontitis and the control groups [16]. This result is consistent with our results regarding the plasma level of the IL-33 but the GCF IL-33 concentration differs from our results. The lower level of GCF samples in chronic periodontitis might be not only due to the GCF volume but may depend also on the sampling site. For this reason, we tried to avoid collection of GCF specimens from quiescent areas, and instead, we collected all GCF samples from the sites with the highest CAL and maximum bleeding score together with radiographic evidence of 
alveolar bone resorption. Another study done by Papathanasiou et al, (2014) measured the IL-33 in the GCF using multiplex assay and they could not detect IL-33 in the GCF of all studied samples from chronic periodontitis subjects and subjects with healthy periodontium and they concluded that there is no association between IL-33 and the periodontal disease and they indicated that the presence of auto antibodies may produce non specific bindings which can prevent the identification of the cytokines in the biological specimens using multiplex assay [17].

Kurşunlu et al, (2015) measured the IL-33 and other cytokines in the GCF in the individuals with gingivitis, chronic periodontitis, generalized aggressive periodontitis and healthy group and they found that the levels of IL-33 in the GCF were indifferent between all studied groups [18]. Their results were also consistent with our results.

Gümüş et al, (2017) showed that the salivary concentration of IL-33 was higher in the chronic periodontitis group even than aggressive periodontitis while serum IL-33 level was indifferent and they could not definitely explain their results but thought that both diseases may have separate pathways and so, they suggested further research [31].

Regarding IL-33 A/G rs1929992 polymorphism, it was studied in several chronic diseases such as systemic lupus erythematosus [32], systemic sclerosis [33], peptic ulcer [34], Behçet's disease [35] and ischemic stroke [36] but not in periodontitis according to our knowledge. We found no association between IL-33 A/G rs1929992 genotype or allele frequencies and the periodontitis in Saudis in Makkah environ. To our knowledge, this is the first report that studied the association between IL-33 A/G rs1929992 polymorphism and the periodontal disease among Saudi subjects.

However, this study is not without limitations especially the small sample size. So, further research will be required using a large periodontitis cohort with clinical data, other methods like evaluation of gene expression of the IL-33 in the gingival tissues or intervention studies are needed to understand the role of the IL33 in periodontal disease.

\section{Conclusion}

Our findings suggested that the GCF and the Plasma IL-33 cannot differentiate between the subjects with healthy periodontium and those with periodontal disease. Also, we concluded that the IL-33 A/G rs1929992 polymorphism may not be associated with the risk of periodontitis among Saudis in Makkah environ, however more genetic analysis with larger sample size and other SNPs and haplotype analysis are required to elucidate the role of IL-33 in the pathogenesis of periodontitis.

\section{Ethical Statement}

The institutional review board of the Faculty of Dentistry, Umm Al Qura University, Saudi Arabia approved the study. These guidelines of the IRB follow the Saudi and International guidelines that follows the Declaration of Helsinki in 1995 (as revised in Fortaleza, Brazil, October 2013). Informed consents were obtained from all participants.

\section{Acknowledgment}

We thank Dr. Abd Elrahman Sabry for his help in the research unit, Um Al-Qura University, Saudi Arabia. Also, we thank Prof. Abd Elaziz Y. for his help in the section of statistics.

\section{References}

[1]. Newman MG, Takei H,Klokkevold PR, Carranza FA (2019) Newman and Carranza's clinical periodontology. 13thedn. Philadelphia; Elsevier.p. 342351.

[2]. Michalowicz BS, Diehl SR, Gunsolley JC, Sparks BS, Brooks CN, Koertge TE,et al. Evidence of a substantial genetic basis for risk of adult periodontitis. J Periodontol. 2000; 71(11): 1699-707.Pubmed PMID: 11128917.

[3]. Borrell LN, Papapanou PN. Analytical epidemiology of periodontitis. J. Clin. Periodontol. 2005 Oct;32:132-58.

[4]. Ohlrich EJ, Cullinan MP, Seymour GJ. The immunopathogenesis of periodontal disease. Aust Dent J. 2009 Sep;54:S2-10.

[5]. Könönen E, Gursoy M, Gursoy UK. Periodontitis: A Multifaceted Disease of Tooth-Supporting Tissues. J Clin Med. 2019 Jul 31;8(8):1135.Pubmed PMID: 31370168.

[6]. Toy VE, Uslu MO. Do genetic polymorphisms affect susceptibility to periodontal disease? A literature review. Niger J Clin Pract. 2019 Apr;22(4):445453.Pubmed PMID: 30975946.

[7]. Chapple IL, Bouchard P, Cagetti MG, Campus G, Carra MC, Cocco F, et al . Interaction of lifestyle, behaviour or systemic diseases with dental caries and periodontal diseases: consensus report of group 2 of the joint EFP/ORCA workshop on the boundaries between caries and periodontal diseases. J Clin Periodontol. 2017 Mar;44(Suppl 18):S39-51.

[8]. Callard RE, Turner MW. Cytokines and Ig switching: evolutionary divergence between mice and humans. Immunol Today. 1990 Jun;11(6):200-3. Pubmed PMID: 2191682.

[9]. da Luz FA, Oliveira AP, Borges D, Brígido PC, Silva MJ. The physiopathological role of IL-33: new highlights in bone biology and a proposed role in periodontal disease. Mediators Inflamm. 2014;2014:342410-7.Pubmed PMID: 24692848.

[10]. Schmitz J, Owyang A, Oldham E, Song Y, Murphy E, McClanahan TK, et al. IL-33, an interleukin-1-like cytokine that signals via the IL-1 receptorrelated protein ST2 and induces T helper type 2-associated cytokines. Immunity. 2005 Nov;23(5):479-90.Pubmed PMID: 16286016.

[11]. Byers DE, Alexander-Brett J, Patel AC, Agapov E, Dang-Vu G, Jin X, et al. Long-term IL-33-producing epithelial progenitor cells in chronic obstructive lung disease. J Clin Invest. 2013 Sep;123(9):3967-82.Pubmed PMID: 23945235.

[12]. Carriere V, Roussel L, Ortega N, Lacorre DA, Americh L, Aguilar L, et al. IL33, the IL-1-like cytokine ligand for ST2 receptor, is a chromatin-associated nuclear factor in vivo. Proc Natl Acad Sci U S A. 2007 Jan 2;104(1):282-7. Pubmed PMID: 17185418.

[13]. Moulin D, Donzé O, Talabot-Ayer D, Mézin F, Palmer G, Gabay C. Interleukin (IL)-33 induces the release of pro-inflammatory mediators by mast cells. Cytokine. 2007 Dec 1;40(3):216-25.

[14]. Komai-Koma M, Gilchrist DS, McKenzie AN, Goodyear CS, Xu D, Liew FY. IL-33 activates B1 cells and exacerbates contact sensitivity. J Immunol. 2011 Feb 15;186(4):2584-91.Pubmed PMID: 21239718.

[15]. Malcolm J, Awang RA, Oliver-Bell J, Butcher JP, Campbell L, Adrados Planell A, et al. IL-33 Exacerbates Periodontal Disease through Induction of RANKL. J Dent Res. 2015 Jul;94(7):968-75.Pubmed PMID: 25808546.

[16]. Sağlam M, Köseoğlu S, Aral CA, Savran L, Pekbağrıyanık T, Çetinkaya A. Increased levels of interleukin-33 in gingival crevicular fluids of patients with chronic periodontitis. Odontology. 2017 Apr;105(2):184-190.Pubmed PMID: 27363844.

[17]. Papathanasiou E, Teles F, Griffin T, Arguello E, Finkelman M, Hanley J, et al. Gingival crevicular fluid levels of interferon- $\gamma$, but not interleukin- 4 or-33 or thymic stromal lymphopoietin, are increased in inflamed sites in patients with periodontal disease. J Periodontal Res. 2014 Feb;49(1):55-61.

[18]. Kurşunlu SF, Oztürk VÖ, Han B, Atmaca H, Emingil G. Gingival crev-

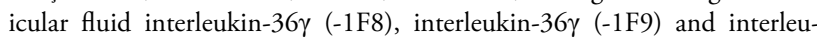
kin-33 (-1F11) levels in different periodontal disease. Arch Oral Biol. 2015 Jan;60(1):77-83.Pubmed PMID: 25247780.

[19]. Ballambettu SP, Pradeep AR, Purushottam M, Sen S. Higher interleukin-33 levels in aggressive periodontitis cases. J Indian Soc Periodontol. 2019 SepOct;23(5):424-429.Pubmed PMID: 31543615. 
[20]. American Academy of Periodontology Task Force Report on the Update to the 1999 Classification of Periodontal Diseases and Conditions. J Periodontol. 2015 Jul;86(7):835-8.Pubmed PMID: 26125117.

[21]. Kaslick RS, Chasens AI, Weinstein D, Waldman R. Ultramicromethod for the collection of gingival fluid and quantitative analysis of its sodium content. J Dent Res. 1968 Nov-Dec;47(6):1192.Pubmed PMID: 5249061.

[22]. Fathi Maroufi N, Gholampour Matin M, Ghanbari N, Khorrami A, Amini $\mathrm{Z}$, Haj Azimian S, et al. Influence of single nucleotide polymorphism in IL27 and IL-33 genes on breast cancer. Br J Biomed Sci. 2019 Apr;76(2):8991.Pubmed PMID: 30406733

[23]. Gemmell E, Seymour GJ. Immunoregulatory control of Th1/Th2 cytokine profiles in periodontal disease. Periodontol 2000. 2004;35:21-41.Pubmed PMID: 15107056.

[24]. Cicchese JM, Evans S, Hult C, Joslyn LR, Wessler T, Millar JA, et al. Dynamic balance of pro- and anti-inflammatory signals controls disease and limits pathology. Immunol Rev. 2018 Sep;285(1):147-167.Pubmed PMID: 30129209 .

[25]. Cekici A, Kantarci A, Hasturk H, Van Dyke TE. Inflammatory and immune pathways in the pathogenesis of periodontal disease. Periodontology 2000. 2014 Feb;64(1):57-80.

[26]. Kurowska-Stolarska M, Hueber A, Stolarski B, McInnes IB. Interleukin-33: a novel mediator with a role in distinct disease pathologies. J Intern Med. 2011 Jan;269(1):29-35.Pubmed PMID: 21158975.

[27]. Heidari Z, Moudi B, Mahmoudzadeh-Sagheb H. Immunomodulatory factors gene polymorphisms in chronic periodontitis: an overview. BMC Oral Health. 2019 Feb 12;19(1):29.Pubmed PMID: 30755190.

[28]. Dinarello CA. The IL-1 family of cytokines and receptors in rheumatic diseases. Nat Rev Rheumatol. 2019 Oct;15(10):612-32.

[29]. Shibata K. Historical aspects of studies on roles of the inflammasome in the pathogenesis of periodontal diseases. Mol Oral Microbiol. 2018 Jun;33(3):203-211.PubmedPMID: 29360244.

[30]. Buduneli N, Özçaka Ö, Nalbantsoy A. Interleukin-33 levels in gingival crevicular fluid, saliva, or plasma do not differentiate chronic periodontitis. J Periodontol. 2012 Mar;83(3):362-8.

[31]. Gümüş P, Nizam N, Nalbantsoy A, Özçaka Ö, Buduneli N. Saliva, Serum Levels of Interleukin-21, -33 and Prostaglandin E2 in Patients with Generalised Aggressive or Chronic Periodontitis.Oral Health Prev Dent. 2017;15(4):385-390.

[32]. Zhu X, Xie L, Qin H, Liang J, Yang Y, Xu J, et al. Interaction between IL-33 Gene Polymorphisms and Current Smoking with Susceptibility to Systemic Lupus Erythematosus. J Immunol Res. 2019 Mar 11;2019:1547578.Pubmed PMID: 30984790.

[33]. Koca SS, Pehlivan Y, Kara M, Alibaz-Oner F, Oztuzcu S, Yilmaz N, et al. The IL-33 gene is related to increased susceptibility to systemic sclerosis. Rheumatol Int. 2016 Apr;36(4):579-84.Pubmed PMID: 26743213.

[34]. Bassagh A, Jafarzadeh A, Kazemipour N, Nemati M, Aminizadeh N, Larussa $\mathrm{T}$, et al. Decreased circulating interleukin-33 concentration in Helicobacter pylori-infected patients with peptic ulcer: Evaluation of its association with a cytokine gene polymorphism, gender of patients and bacterial virulence factor CagA. MicrobPathog. 2019 Nov 1;136:103708.

[35]. Koca SS, Kara M, Deniz F, Ozgen M, Demir CF, Ilhan N, et al. Serum IL33 level and IL-33 gene polymorphisms in Behçet's disease. Rheumatol Int. 2015 Mar;35(3):471-7.Pubmed PMID: 25119832.

[36]. Guo L, Zhou X, Guo X, Zhang X, Sun Y. Association of interleukin-33 gene single nucleotide polymorphisms with ischemic stroke in north Chinese population. BMC Med Genet. 2013 Oct 9;14:109.Pubmed PMID: 24107076. 